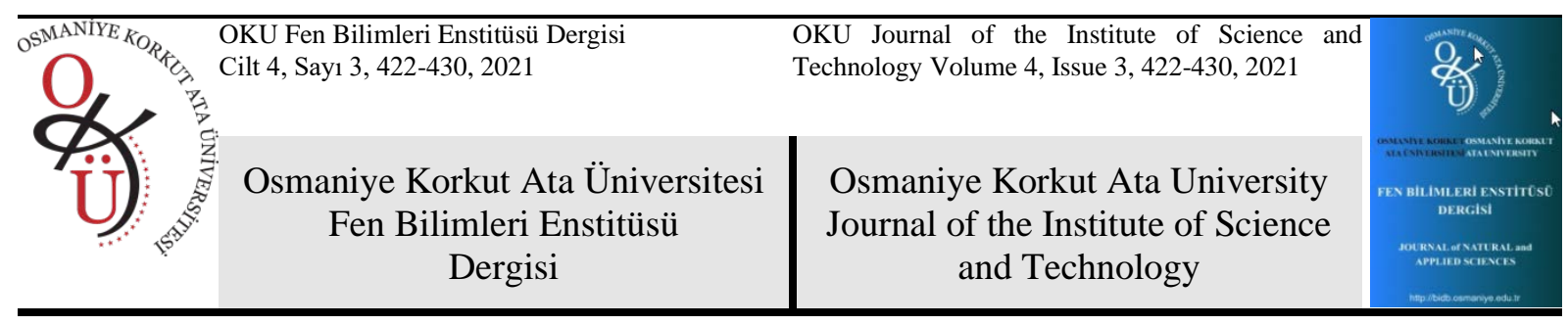

\title{
PVA/Kitosan Biyomalzemelerin İlaç Salım Mekanizmasında Çapraz Bağlayıcı Etkisinin İncelenmesi
}

\author{
Seda Ceylan ${ }^{*}$ \\ ${ }^{1}$ Adana Alparslan Bilim ve Teknoloji Üniversitesi, Mühendislik Fakültesi, Biyomühendislik Bölümü, 01250, Adana \\ ${ }^{1}$ https://orcid.org/0000-0002-1088-7886 \\ *Sorumlu yazar: sceylan@atu.edu.tr
}

\begin{tabular}{|c|c|}
\hline Araştırma Makalesi & ÖZET \\
\hline $\begin{array}{l}\text { Makale Tarihçesi: } \\
\text { Geliş tarihi: } 19.07 .2021 \\
\text { Kabul tarihi:01.11.2021 } \\
\text { Online Yayınlanma: } 15.12 .2021\end{array}$ & $\begin{array}{l}\text { Bu çalışmada, polivinil alkol (PVA) ve kitosan temelli; kimyasal olarak } \\
\text { çapraz bağlanmış hidrojeller üretilmiştir. Kitosan, biyolojik olarak uyumlu, } \\
\text { toksik olmayan ve doğal bir polimerdir. PVA, suda çözünebilen, toksik } \\
\text { olmayan ve biyolojik olarak bozunur bir sentetik polimerdir. Hidrojellerin } \\
\text { mekanik özelliklerini ve biyouyumluluk özelliklerini geliştirmek için; }\end{array}$ \\
\hline $\begin{array}{l}\text { Anahtar Kelimeler: } \\
\text { PVA } \\
\text { Kitosan } \\
\text { Genipin } \\
\text { Gluteraldehit } \\
\text { Rodamin B }\end{array}$ & $\begin{array}{l}\text { kitosan ve PVA polimerlerleri birlikte kullanılmıştır. Çapraz bağlayıcı ve } \\
\text { çapraz bağlayıcı miktarının değişikliği sentez parametreleri olarak } \\
\text { çalışılmıştır. Kimyasal çapraz bağlayıcıların (genipin ve gluteraldehit) } \\
\text { hidrojelin karakterizasyonu üzerine etkisi analiz edilmiştir. Kimyasal yapı ve } \\
\text { gözenek morfolojisi, Fourier transform infrared spektroskopi (FTIR) ve } \\
\text { Taramalı elektron mikroskobu (SEM) ile gösterilmiştir. Hidrojellerin şişme } \\
\text { oranı belirlenmiş görsel olarak sunulmuştur. Bu çalışmalara ek olarak, } \\
\text { rodamin B model ilaç kullanılarak, hidrojellerin salım mekanizması } \\
\text { araştırılmıştır. }\end{array}$ \\
\hline
\end{tabular}

Investigation of the Crosslinker Effect on the Drug Release Mechanism of PVA/Chitosan Biomaterials

\section{Research Article}

Article History:

Received: 19.07.2021

Accepted: 01.11.2021

Published online: 15.12.2021

\section{Keywords:}

PVA

Chitosan

Genipin

Gluteraldehyde

Rhodamine B

\begin{abstract}
The present study aims to produce different crosslinked hydrogels based on poly vinyl alcohol (PVA) and chitosan. Chitosan is a biocompatible, nontoxic and natural polymer and attracted considerable interest in a wide range of biomedical and pharmaceutical applications. PVA is a water soluable, nontoxic, flexible and biodegradable synthetic polymer. In order to improve mechanical properties and biocompatibility of scaffolds; chitosan and PVA polymers were used. PVA to chitosan weight ratio and concentration of the crosslinking agent were studied as synthesis parameters. Effect of chemical crosslinkers (genipin and sulfiric acid) on the hydrogel properties were analysed. Chemical structure and pore morphology were demonstrated by Fourier transform infrared spectroscopy (FTIR) and Scanning electron microscopy (SEM). Swelling ratio and degradation profile of the scaffolds were also determined. In addition to this, drug (Rhodamine B) release models from hydrogels were investigated.
\end{abstract}

To Cite: Ceylan S. PVA/Kitosan Biyomalzemelerin İlaç Salım Mekanizmasında Çapraz Bağlayıcı Etkisinin İncelenmesi. Osmaniye Korkut Ata Üniversitesi Fen Bilimleri Enstitüsü Dergisi 2021; 4(3): $422-430$. 


\section{Giriş}

Biyomalzemeler, dokuların işlevlerini yerine getirmek veya iyileştirmek amacıyla canlı vücudunda kullanılan doğal ya da sentetik malzemelerdir (Yapar, 2009). Etken Madde Salım sistemlerinde de kullanılan biyomalzemeler, diyabet, kanser, göz tansiyonu gibi sürekli ilaç kullanımını gerektiren hastalıklar için umut verici olmaktadır (Akman, 2007). Bu temel soruna odaklanan kontrollü ilaç salımı uygulamalarında amaç; ilacın vücut içerisindeki hedefini, yayılımını, zamanlamasını veya dozunu kontrol etmektir. İlaçların vücutta etkili olduğu miktar aralığı değişmektedir. Etkili miktardan fazla veya az kullanım yan etkilere sebep olabilir. Bu nedenle klasik yaklaşımın aksine, kontrollü ilaç salımı sayesinde vücuttaki ilaç miktarı bu etkin alanda daha hassas bir biçimde tutularak tedavi olasılığı arttırılırken, ilaç tasarrufu da sağlanabilmektedir (Kurtoğlu ve Karataş, 2009). Ayrıca kontrollü ilaç salım sistemleri sayesinde ilacın vücutta belirli bir bölgede etki göstermesi hedeflenmektedir. $\mathrm{Bu}$ yüzden, doku mühendisliği yaklaşımı ile üretilmiş kontrollü ilaç salımı uygulamalarında kullanılan biyomalzemeler ile ilgili çalışmalar son yıllarda artış göstermiştir (Bodde ve ark., 2008; Akdemir, 2009; Liu ve ark., 2014; Mahor ve ark., 2016).

$\mathrm{Bu}$ uygulamalarda kullanılan doğal polimerler, biyolojik olarak üretilen ve benzersiz işlevsel özelliklere sahip olan polimerlerdir. Proteinler (örneğin kollajen, jelatin, elastin, aktin, vb), polisakkaritler (selüloz, nişasta, dekstran, kitin, vb) ve polinükleotidler (DNA ve RNA) başlıca doğal polimerlerdir. Yaşayan organizmaların karmaşık yapılarından dolayı üretim maliyetlerinin yüksek oluşu ve yeterince büyük ölçeklerde üretilememeleri, bu polimerlerle ilgili karşılaşılan başlıca sorunlardandır. Doğal polimerler, sahip oldukları işlevsel özellikler nedeniyle değişik kullanım alanlarına sahipler. Kalınlaştırıcı, jel yapıcı, bağlayıcı, dağıtma ajanı, kayganlaştırıcı, yapışstırıcı ve biyomalzeme olarak kullanılabilmektedirler (Maviş ve Karakeçili, 2007; Akdemir, 2009).

Doğal polimerler, biyomalzeme alanının vazgeçilmez kaynaklarıdır. Biyolojik ortamdaki makro moleküllerin benzeri veya aynısı olduklarından, canlı vücuduyla temas ettiklerinde toksik etki gösterme, enfeksiyona sebep olma, gibi istenmeyen reaksiyonlara sebep olmazlar. Ancak, elde edildikleri kaynağa bağlı olarak bileşimlerinin değişmesi, yüksek sıcaklıklarda bozunmaları ve bu nedenle şekillendirilmelerindeki güçlük ve tüm bunların ötesinde immünojenik olmaları (bağışıklık tepkisine yol açmaları) önemli dezavantajlarıdır. Enzim varlı̆̆ında yapılarının bozunması, yani biyobozunur olmaları ise geçici uygulamalarda kullanılan biyomalzemeler açısından avantajdır.

Sentetik polimerler ise özellikle ortopedik cerrahide fiksasyon ve dikiş materyali formlarında güvenle ve yaygın olarak kullanılmaktadır. Kıkırdak doku mühendisliğinde de hücrelerin yerleştirildiği üç boyutlu iskeleti oluşturmak için çok değişik sentetik polimer seçenekleri üzerinde durulmuştur (Akdemir, 2009; Goy ve ark., 2009; Bedian ve ark., 2017).

$\mathrm{Bu}$ makalede ise hedef; doku mühendisliği uygulamalarında kullanılabilecek Polivinil Alkol PVA (sentetik)/Kitosan (doğal) polimer temelli biyouyumlu; hücre büyümesini ve dokudaki besin alışverişini desteklemesi için gözenekli; iyileşme boyunca doku iskelesinin vücuttan kolaylıkla uzaklaştırılabilmesi için biyobozunur özelliklere sahip malzeme üretmek ve salım mekanizmasını 
incelemektir (Biswas ve ark., 2017). Çapraz bağlayıcı olarak genipin ve gluteraldehit kullanılmıştır. $\mathrm{Bu}$ çalışmada aynı anda çapraz bağlayıcı oranının malzeme karakterizasyonu üzerindeki etkisi de incelenmiştir (Kaparekar ve ark., 2020). Fourier Dönüşümlü Infrared Spektrofotometre (FTIR) üretilen hidrojellerin kimyasal gruplarını incelemek için kullanılırken, Taramalı elektron mikrokobu (SEM) malzemelerin yüzey morfolojisini incelemek için kullanılmıştır. Ayrıca şişme profili belirlenmiştir. Ayrıca üretilen biyomalzemelere rodamin B model ilaç eklemesi yapılarak salım kinetiği incelenmiştir. Bu bölümde üretilen biyomalzemenin kontrollü ilaç salım uygulamalarında kullanılmasına yönelik ön çalışmalar bu model ilaç kullanılarak yapılmış ve belirlenen zaman aralığında salınan boya miktarı hesaplanmıştır.

\section{Materyal ve Metot}

$\mathrm{Bu}$ çalışmada kullanılan kitosan (düşük moleküler ağılıklı) ve PVA Sigma Aldrich (ABD) firmasından alınmıştır. Çapraz bağlayıcı olarak kullanılan genipin (GP), Gluteraldehit (GA) ve Rodamin B Sigma Aldrich (ABD) firmasından tedarik edilmiştir. Çözücü olarak kullanılan asetik asit ise Merck (Almanya) firmasından alınmıştır.

\section{Hidrojellerin Üretim Prosesi}

Kitosan ve PVA polimerinden oluşan doku iskeleleri iki farklı şekilde kodlanmıştır. Genipin kullanılarak çapraz bağlanarak üretilen hidrojeller PVA/KITT-GP olarak kodlanırken gluteraldehit kullanılarak üretilen hidrojeller PVA/KİT-GA olarak kodlanmıştır. Tüm grafik ve karşıllaştırmalarda aynı kod sistemi kullanılmıştır.

Kitosan \%6 asetik asit içerisinde çözdürülürken, PVA deiyonize su içerisinde $90{ }^{\circ} C^{\prime}$ de çözdürülmüştür. Eklenen GP ve GA miktarı Tablo 1’de gösterilmektedir.

Tablo 1. Üretilen hidrojeller ve kullanılan çapraz bağlayıcı miktarları

\begin{tabular}{cc}
\hline Hidrojel Kodu & GA/GP miktarı $(\boldsymbol{\mu l})$ \\
\hline PVA-KİT 10 GA & 10 \\
PVA-KİT 20 GA & 20 \\
PVA-KİT 10 GP & 10 \\
PVA-KİT 20 GP & 20 \\
\hline
\end{tabular}

$\mathrm{Bu}$ hidrojellerde kitosan oran $\% 1 \mathrm{w} / \mathrm{v}$ olarak sabit tutulurken PVA oran 1 da $\% 3(\mathrm{w} / \mathrm{v})$ olarak sabit tutulmuştur. $\mathrm{Bu}$ çalışmada GP \%0,025 w/v oranında hazırlanırken, GA \%3 (v/v) oranında hazırlanmıştır.

Hazırlanan polimer çözeltilerinden $1 \mathrm{ml}$ alınarak karıştırılır ve homojen bir yapı elde edilir. Daha sonra belirlenen çapraz bağlayıcı miktarı eklenir ve petrilere alınır. Son olarak $40{ }^{\circ} \mathrm{C}$ de 24 saat bekletilerek filmler elde edilir.

Üretim prosesini gösteren şema Şekil 1'de gösterilmiştir. 


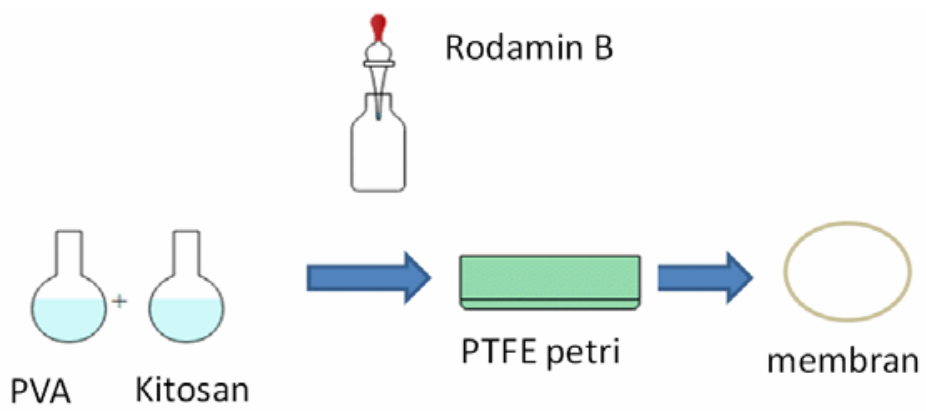

Şekil 1. Membranların üretim prosesi

\section{Hidrojellerin Karakterizasyonu}

Üretilen hidrojellerin kimyasal yapısı FT-IR Perkin Elmer-Fourier Dönüşümlü İnfrared Spektrometre (FT-IR/FIR/NIR Spectrometer Frontier -ATR, ABD) ile analiz edilmiştir. Analizler 500-4000 $\mathrm{cm}^{-1}$ dalga boyları arasında yapılmıştır.

Hidrojellerin morfolojisini belirlemek için taramalı elektron mikroskobu (FE-SEM Zeiss/Supra55, Quanta 400F Field Emission, ABD) kullanılmıştır. Elektrik iletkenliğini sağlayabilmek için, hidrojellerin yüzeyi platin/karbon ile kaplanmış ve SEM görüntüleri elde edilmiştir. SEM, $5 \mathrm{kV}$ da çalıştırılmıştır. SEM görüntüleri, Taramalı elektron mikroskobuyla 50000 ve 100000 büyütme oranlarında elde edilmiştir.

Farklı çapraz bağlayıcı ve polimer oranı kullanılarak hazırlanan hidrojellerin şişme oranının eşitlik 1 kullanılarak belirlenmiştir. Bu analizde kuru ağırlıklar ölçülmüş ve daha sonra örnekler distile suya konularak belirlenen zaman değerlerinde ağırlık ölçümleri yapılmıştır. Yüzey üzerindeki fazla suyun alınması için, her tartımdan önce filtre kâğıdı kullanılarak örneklerin fazla suyu alınmıştır.

Eşitlik (1)'de şişme oranının hesaplanması için kullanılan formül belirtilmiştir. Mt: Şişme oranı, Mi: ilk ağırlık ve Mf: son ağırlık olarak tanımlanmıştır (Güneş ve Tihmınlıoğlu, 2017).

$\operatorname{Mt}(\%)=[M f-M i)] / M i] \times 100$

Çalışmanın ilaç salım bölümünde PVA-KİT hidrojelleri üretildikten sonra rodamin B stok boya solüsyonundan $(0,1 \mathrm{~g} / \mathrm{L}) 40 \mu \mathrm{l}$ alınarak hidrollere eklenmiş ve solüsyonu tam çekmesi için 24 saat süreyle bekletilmiştir. Daha sonra tüplere yerleştirilen hidrojellerin üzerine $8 \mathrm{ml}$ su eklenerek ve her saat absorbans değerleri okunmuştur ( $\mathrm{n}=3$, Shimadzu UV-VIS, UVmini-1240, Japan). Belirlenen zaman aralıklarında tüplerden $3 \mathrm{ml}$ alınarak küvetlere yerleştirilmiş ve okuma yapılmıştır. Daha sonra okunan $3 \mathrm{ml}$ çözelti yerine yeni $3 \mathrm{ml}$ su eklenmiştir ve bu şekilde salım değerlerine ulaşılmıştır. İlaç enkapsülasyon verimliliği hesaplamalarında kullanılan denklem eşitlik 2'de belirtilmiştir.

(EE),\% = (İlk çözeltideki ilacın ağırlığı-Çözeltide kalan ilacın ağırlığı)/ İlk çözeltideki ilacın ağırlığı (2) 


\section{Bulgular ve Tartışma}

Bu bölümde, üretilen PVA/Kit hidrojellerin analiz sonuçları farklı başlıklar altında incelenmektedir. Değişen çapraz bağlayıcı neticesinde, hazırlanan hidrojellerin FT-IR sonuçları, SEM analizleri, şişme davranışları ve salım kinetikleri karşılaştırılmalı olarak yorumlanmıştır.

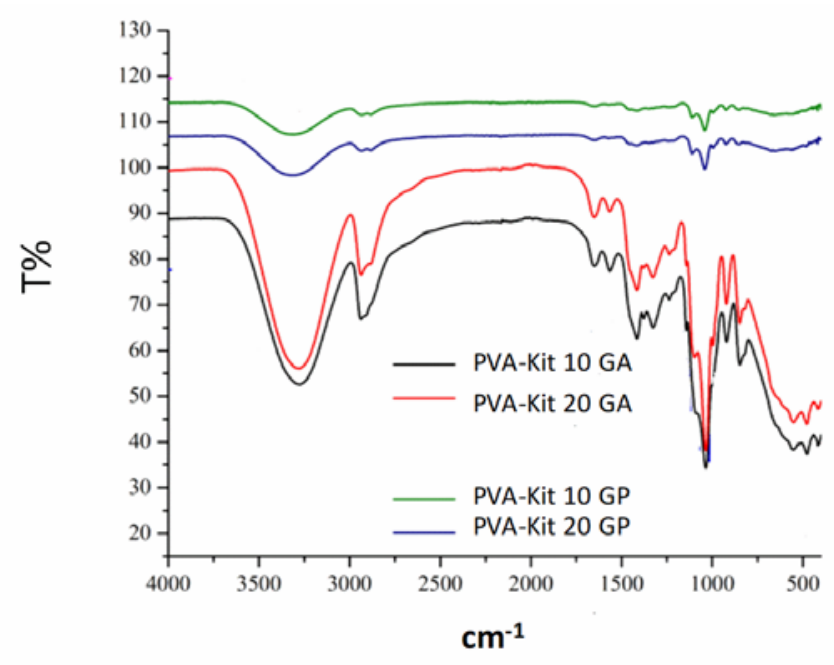

Şekil 2. Filmlerin FTIR spektrumları

Farklı çapraz bağlayıcı kullanılarak elde edilen PVA-Kit yapı iskelelerinin FTIR spektroskopisi ile elde edilen sonuçlar Şekil 2'de gösterilmektedir. 1600-1750 cm-1'deki pik, karboksilatın küçük kayması yoluyla kitosan ve PVA'nın ortak piklerine karşılık gelir. Hidroksil gruplarının titreşimleri ise $3400 \mathrm{~cm}^{-1}$ de görüntülenen güçlü ve geniş tepeye karş1lık gelmektedir (Ahmed ve ark., 2018). 3300$3400 \mathrm{~cm}^{-1}$ de N-H varlığı, PVA ve kitosan arasındaki C-N bağının oluştuğunu gösterir.

Buna ek olarak, filmlerin GA ile çapraz bağlanması, $1646 \mathrm{~cm}^{-1}$ de pik zirvesine neden olur (imin bağları N=C) (Nazemi ve ark., 2014). $1562 \mathrm{~cm}^{-1}$ de etilenik bağ frekansının yoğunluğu, GA konsantrasyonu ile artmıştır. $2936 \mathrm{~cm}^{-1}$ deki tepe noktası ise $\mathrm{C}-\mathrm{H}$ germe titreşim frekansına karşıllı gelmektedir. Ek olarak, $1100 \mathrm{~cm}^{-1}$ deki pik, alifatik amino gruplarını gösterir (Demir ve ark., 2016).

$900-1000 \mathrm{~cm}^{-1}$ deki pikler, birincil amin gruplarıyla genipinin heterosiklik yapısının oluşumuyla moleküller arası ve çapraz bağlama bağlarının oluşumunu gösteren çapraz bağlı poli vinil alkol ve kitosan yap1 iskelelerini gösterir. Bu bağın ortaya çıkması, genipin kullanılarak PVA ve kitosan arasında başarılı bir çapraz bağlantı elde edilebildiğini göstermiştir (Nguyen ve ark., 2016) 

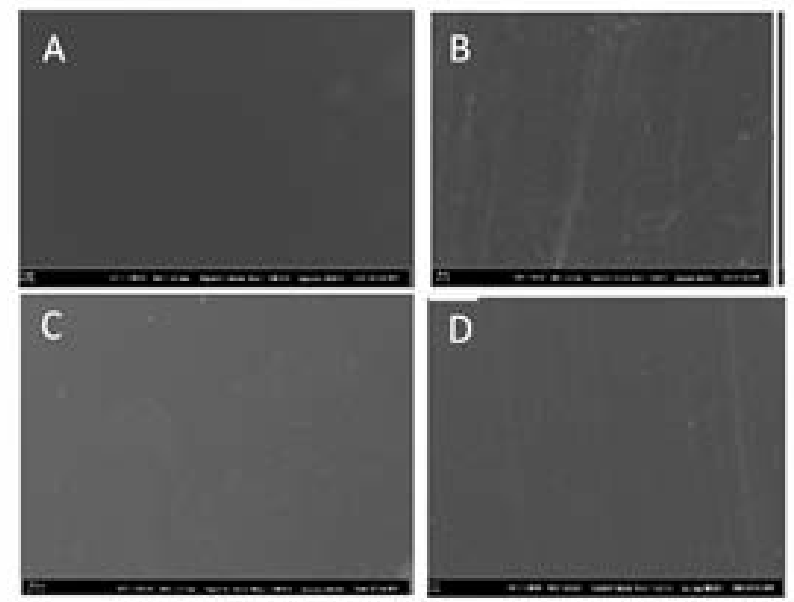

Şekil 3. Filmlerin SEM görüntüleri A) PVA-Kit 10GA, B) PVA-Kit 20GA, C) PVA-Kit 10GP, PVA-Kit 20GP(büyüklük : 5000x)

Tüm filmlerin yüzey yapısını inceleyen SEM görüntüleri Şekil 3’te gösterilmiştir. Yüzeylerin homojen bir yapıya sahip olduğu görülmektedir.

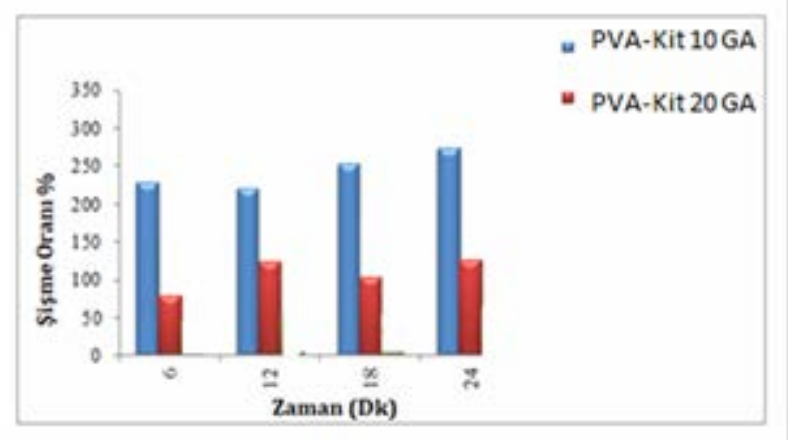

Şekil 4. Gluteraldehit ile çapraz bağlanan filmlerin şişme değerleri

Bu bölümde Şekil 4 ve 5’te gluteraldehit ve genipin ile çapraz bağlanan PVA-Kitosan hidrojellerin şişme oranları hesaplanmıştır. Doku iskelelerinin şişme oranı analizleri, malzemenin doku sıvısı ile birlikte alacağ 1 hacmi hesaplamak için önem arz etmektedir. Sabit polimer konsantrasyonunda hazırlanan hidrojellerde tek değişken çapraz bağlayıcı miktarıdır. Şekil 4'de PVA-KİT10GA hidrojelin şişme oranı 6. dakikada \%225 değerlerine ulaşırken, PVA-KİT20GA hidrojelinin şişme değeri \%65 değerine ulaşmıştır. Çapraz bağlayıcı malzemenin karakterizasyon özellikleri üzerinde etkilidir. Ayrıca Şekil 5’te iki farklı genipin konsantrasyonunda üretilen hidrojellerin şişme değerleri görülmektedir. Çapraz bağlayıcı miktarı arttıkça şişme değerleri azalmaktadır. Bu durum artan kimyasal bağ nedeniyle açıklanabilir. 


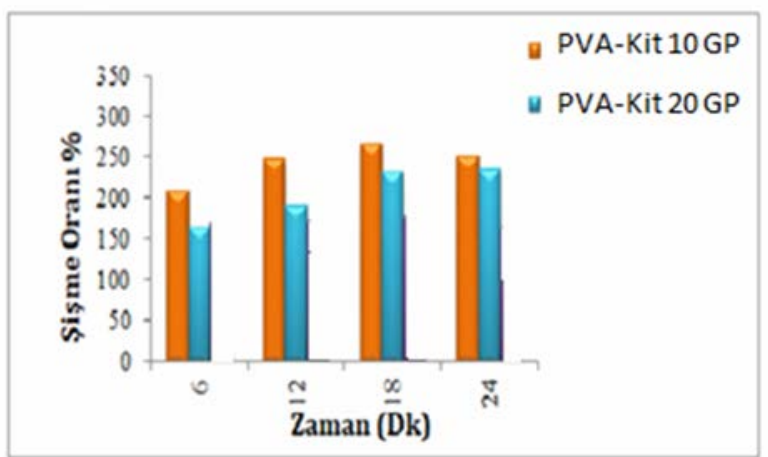

Şekil 5. Genipin ile çapraz bağlanan filmlerin şişme değerleri

Bu bölümde PVA-KİT10GP ve PVA-KİT10GA hidrojellerine yüklenen rodamin B ilacı ile salım çalışmalarının sonuçlarına yer verilmiştir. İlk olarak hazırlanan stok solusyonu farklı oranlarda seyreltilerek kalibrasyon eğrisi elde edilmiştir.

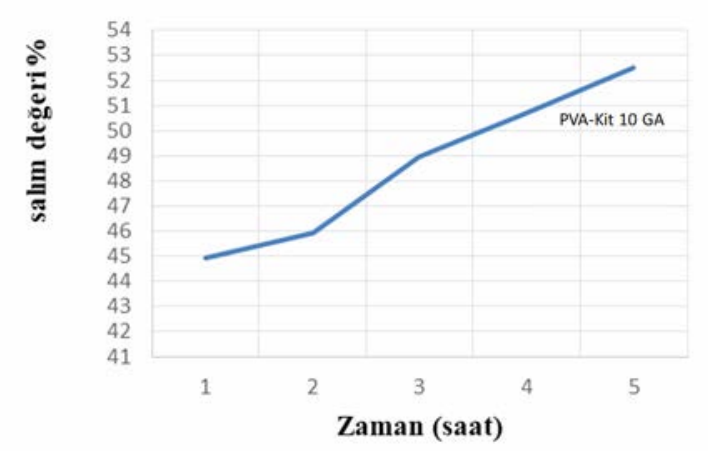

Şekil 6. Gluteraldehit ile çapraz bağlanan PVA-KİT 10 GA filmin salım grafiği

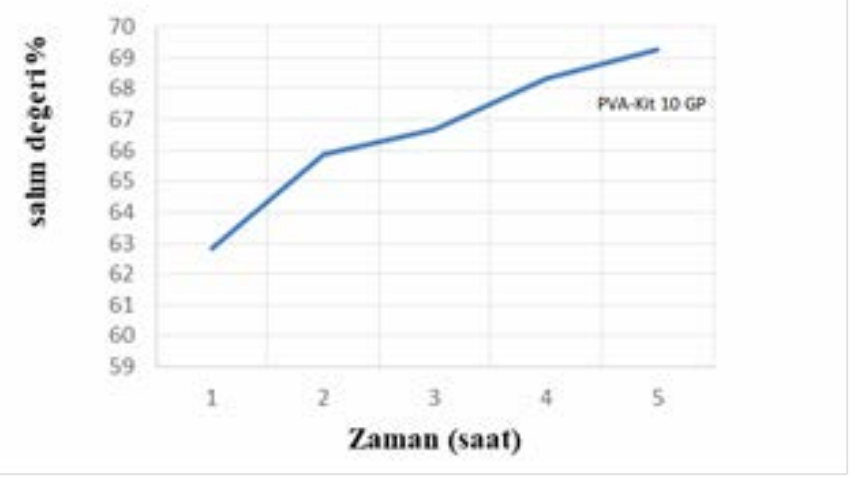

Şekil 7. Genipin ile çapraz bağlanan PVA-KİT 10 GP filmin salım grafiği

Şekil 6 ve 7 salınan ilaç miktarının zamana göre oranını göstermektedir. Grafiklerden de anlaşılacağı gibi genipin ve gluteraldehit farkı salım miktarına etki etmiştir. Beşinci saatin sonunda PVA-KITT10GP hidrojeli \%69,54 oranında ilaç salarken, PVA-KİT10GA hidrojeli \%52,24 oranında ilaç salımı yapmıştır. Burada hedeflenen, belirlenen zaman aralığında salımı istenen ilacın miktarına göre malzeme seçimi yapılabilmektir. Daha hızlı salım isteniyor ise PVA-KIT10GP hidrojeli kullanılabilir. 
Ancak daha yavaş bir salım hedefleniyor ise PVA-KİT10GA hidrojeli kullanılabilir. Burada amaç hedeflenen zamanda, hedeflenen ilaç miktarının salımının yapılmasıdır. Ayrıca diğer parametrelerle (polimer miktarı, sıcaklık vb) ile malzeme karakterizasyonu üzerinde değişiklikler öngürülebilmektedir.

\section{Sonuç}

$\mathrm{Bu}$ çalışma kapsamında, iki farklı çapraz bağlayıcı (genipin, gluteraldehit) ile üretilen hidrojellerin karakterizasyonuna yönelik analizler yapılmıştır.

Değişen çapraz bağlayıcının jeller üzerindeki etkisi incelendiğinde genipin ile çapraz bağlanan hidrojellerin şişme oranının daha yüksek olduğu gözlemlenmiştir. Karakterizasyon çalışmaları, farklı çapraz bağlayıcı ile üretilen PVA/Kitosan hidrojellerin şişme profillerinin ve salım mekanizmasının farklı olduğunu ortaya koymuştur. FTIR ile yapılan analizlerde ise, çapraz bağlanma sonucunda oluşan kimyasal bağlar incelenmiş ve literatür ile karşılaştırılmıştır.

Rodamin B ile yapılan salım çalışmalarında ise; grafiklerin işaret ettiği gibi, genipin ve gluteraldehit ile çapraz bağlanan hidrojellerin salım oranı farklılık göstermiştir. Bundan sonraki çalışmalarda üretilen hidrojellerin biyouyumluluğu araştırılacaktır.

\section{Çıkar Çatışması Beyanı}

Bu makalede herhangi bir çıkar çatışması bulunmamaktadır.

\section{Araştırmacıların Katkı Oranı Beyan Özeti}

Yazar makaleye \%100 oranında katkı sağlamıştır.

\section{Kaynakça}

Ahmed R., Tariq M., Ali I., Asghar R., Noorunnisa Khanam P., Augustine R., Hasan A. Novel electrospun chitosan/polyvinyl alcohol/zinc oxide nanofibrous mats with antibacterial and antioxidant properties for diabetic wound healing. Int J Biol Macromol 2018; 120: 385-393.

Akdemir ZS. Doku mühendisliğinde kullanılacak yeni polimerik biyomalzemelerin geliştirilmesi. Marmara Üniversitesi Fen Bilimleri Enstitüsü 2009.

Akman AC. Periodontal doku mühendisliği uygulamaları için kitosan temelli doku iskelelerinin üretilmesi, kemik morfojenik protein-2 (BMP-2), bazik fibroblast büyüme faktörü (bFGF), deksametazon (dex) salım kinetiklerinin ve in vitro etkinliklerinin tayini. Hacettepe Üniversitesi 2007.

Bedian L., Villalba-Rodríguez AM., Hernández-Vargas G., Parra-Saldivar R. Iqbal HMN. Bio-based materials with novel characteristics for tissue engineering applications - A review. Int J Biol 
Macromol 2017; 02(98): 837-846.

Biswas DP., Tran PA., Tallon C., O’Connor AJ. Combining mechanical foaming and thermally induced phase separation to generate chitosan scaffolds for soft tissue engineering. J Biomater Sci Polym Ed 2017; 28(2): 207-226.

Bodde EWH., Boerman OC., Russel FGM., Mikos AG., Spauwen PHM., Jansen JA. The kinetic and biological activity of different loaded rhBMP-2 calcium phosphate cement implants in rats. $\mathrm{J}$ Biomed Mater Res - Part A 2008; 87(3): 780-791.

Demir D., Öfkeli F., Ceylan S., Bölgen N. Extraction and characterization of chitin and chitosan from blue crab and synthesis of chitosan cryogel scaffolds. J Turkish Chem Soc Sect A Chem 2016; 3(3): 131-144.

Goy RC., Britto D De., Assis OBG. A review of the antimicrobial activity of chitosan. Polim Cienc e Tecnol 2009; 19(3): 241-247.

Güneş S., Tıhmınlıoğlu F. Hypericum perforatum incorporated chitosan films as potential bioactive wound dressing material. Int J Biol Macromol 2017; 102: 933-943.

Kaparekar PS., Pathmanapan S., Anandasadagopan SK. Polymeric scaffold of Gallic acid loaded chitosan nanoparticles infused with collagen-fibrin for wound dressing application. Int J Biol Macromol 2020; 165: 930-947.

Kurtoğlu AH., Karataş A.Yara tedavisinde güncel yaklaşimlar: Modern yara örtüleri. Ankara Univ Eczac Fak Derg 2009; 38(3): 211-232.

Liu Y., Ren L., Long K., Wang L., Wang Y. Preparation and characterization of a novel tobramycincontaining antibacterial collagen film for corneal tissue engineering. Acta Biomater 2014; 10(1): 289-299.

Mahor A., Prajapati SK., Verma A., Gupta R., Iyer AK., Kesharwani P. Moxifloxacin loaded gelatin nanoparticles for ocular delivery: Formulation and in-vitro, in-vivo evaluation. J Colloid Interface Sci 2016; 483: 132-138.

Maviş B., Karakeçili A. Doku mühendisliğinde nanoteknoloji. 2007 Tübitak.

Nazemi K., Moztarzadeh F., Jalali N., Asgari S., Mozafari M. Synthesis and characterization of poly (lactic-co-glycolic) acid nanoparticles-loaded chitosan/bioactive glass scaffolds as a localized delivery system in the bone defects. Biomed Res Int 2014; 1-9.

Nguyen TH., Ventura R., Min YK., Lee BT. Genipin cross-linked polyvinyl alcohol-gelatin hydrogel for bone regeneration. J Biomed Sci Eng 2016; 09(09): 419-429.

Yapar EA., In situ oluşum yolu ile meydana gelen enjekte edilebilen implant formunda sürekli etkili ilaç salım sistemlerinin geliştirilmesi. Ankara Üniversitesi 2009; Ankara. 